\title{
Modernization of Light Industry of Kazakhstan on the Basis of Integration Effects
}

\author{
Aimen Anuarbek Talkayevich ${ }^{1}$, Atasheva Darya ${ }^{2}$, Khazhgalieva Dina ${ }^{3}$, Sarbasova Gulmira ${ }^{4}$, \\ Kaldygozova Meruert ${ }^{5}$
}

Faculty of Technology, M. Kh. Dulaty Taraz Regional University, Taraz, Republic of Kazakhstan

\section{Email address:}

aimenov_111@mail.ru(A.A. Talkayevich),datasheva07@mail.ru(A. Darya),dina-mx@mail.ru (K. Dina),gulimjan@mail.ru(S.Gulmira), meruert-75@mail.ru(K. Meruert)

\section{To cite this article:}

Aimen Anuarbek Talkayevich, Atasheva Darya, Khazhgalieva Dina, Sarbasova Gulmira, Kaldygozova Meruert. Modernization of Light Industry of Kazakhstan on the Basis of Integration Effects. American Journal of Mechanical and Industrial Engineering.

Vol. 6, No. 5, 2021, pp. 56-61. doi: 10.11648/j.ajmie.20210605.11

Received: August 4, 2021; Accepted: September 6, 2021; Published: September 10, 2021

\begin{abstract}
The main objective of the work is to analyze, model, and develop a strategy for the light industry of Kazakhstan based on the integration effects of industry enterprises coordinated activities, taking into account the impact of the production function of value-added on the prices of commodity products. To achieve this goal, the following tasks are solved: - analysis of trends in the development of light industry in Kazakhstan at the present stage of scientific and technological progress; construction of a quarterly predictive model in the system of macroeconomics; setting the task of digitalizing the development of human capital using the developments of Kazakhstani scientists; models of added value in the integration processes of modernization of light industry in Kazakhstan. In the reproduction process of goods and services, three types of social relations emerge, which arise as a consequence of the development of the productive forces of the human capital in three spheres of its expedient activity. These are the areas of development: macroeconomic policy, structural policy, assessment of the regulatory impact on the economy, both from the side of macroeconomic policy and from the side of structural policy. Kazakhstan has all the prerequisites for the development of light industry - state support, basic production, human resources. To date, the production facilities of textile production have been modernized and can produce high-quality textile products. Kazakhstan's textile products meet the requirements of generally accepted international standards and regulations, which makes it possible to trade in foreign markets. The relevance of the formation of digital strategic management is confirmed by the growth of the information and communication sector of the economy on a global scale. The results of the study of modern digital transformation of companies allowed us to establish that new business models are designed based on digital platforms and are based on the processes of buying and selling not only goods and/or services.
\end{abstract}

Keywords: Added Cost, Development Tendencies, Economic and Mathematical Model, Digitalization of Industry

\section{Introduction}

The study of world experience made it possible to conclude in the development of light industry that the main enterprises of light industry are medium and small enterprises in developing and developed countries. But in order for them to work or exist, large complexes are needed for the processing of raw materials and the production of auxiliary materials. This is the processing of cotton, hides, wool, and production of fabric, threads, and synthetic materials: padding polyester, rubber, synthetic threads, etc. Thus, it is necessary to create a foundation for the development of small and medium-sized businesses (SMBs). For example, in Italy and Spain there are a number of small enterprises that have no difficulty in purchasing materials and related products for tailoring and their own production. There is an excellent example of the firm Zara, which does not have its own production facilities; it designs clothes and commissions small private ateliers (mostly located in Spain). Thus, entrepreneurs can produce a variety of their products and promptly provide fashionable trending items to buyers; no more than 15 days pass from the moment of showing to the 
counter. For example, after showing the Hermes brand in Paris with a new trend, in 15 days we can buy a similar item in a store, regardless of its location.

The state seeks to develop SMBs, creating prosperity and prosperity, because it forms the country's GDP, not oil. Light industry is mainly SMB. Features prevail here: quick return on investment; low production costs; does not require large investments; mobility when changing the assortment of goods; affects the country's defense; affects the health of citizens [1].

As shown above, in an Industry 4.0 world, complexity management is a competitive advantage for cost-added systems. Optimal allocation of cost creation across ecosystems (producing consumer, horizontal integration) results in low complexity costs and high profit margins. Moreover, the optimal distribution of functional services in the cyber-physical system architecture (cloud against fog, vertical integration) leads to economies of scale and high functional adaptability throughout the entire life cycle. Massive forecasts of the future based on the digital shadow (big data in real time) create the foundation for the high technological capabilities of complex systems. In future assembly systems, typical factors that increase flexibility and variability become relevant to ensure a competitive and efficient assembly system. Such factors include versatility, portability, scalability, modularity, and compatibility of system elements and connections. Accordingly, the interdependencies of system elements must be reduced and made more independent, and modular elements or fractals must be created. The main characteristics of modular assembly are independent modular assembly stations [2]. The Industrial Data Initiative was created jointly by representatives of the business, political and research communities in Germany at the end of 2014 and since then it has set a goal of development and use in Europe and the world. The research project of the same name FraunhoferGesellschaft with the support of the Federal Ministry of Education and Research (FMER) is aimed at developing a conditional architecture model for industrial data space and its direction in individual applications (Figure 1) [3].

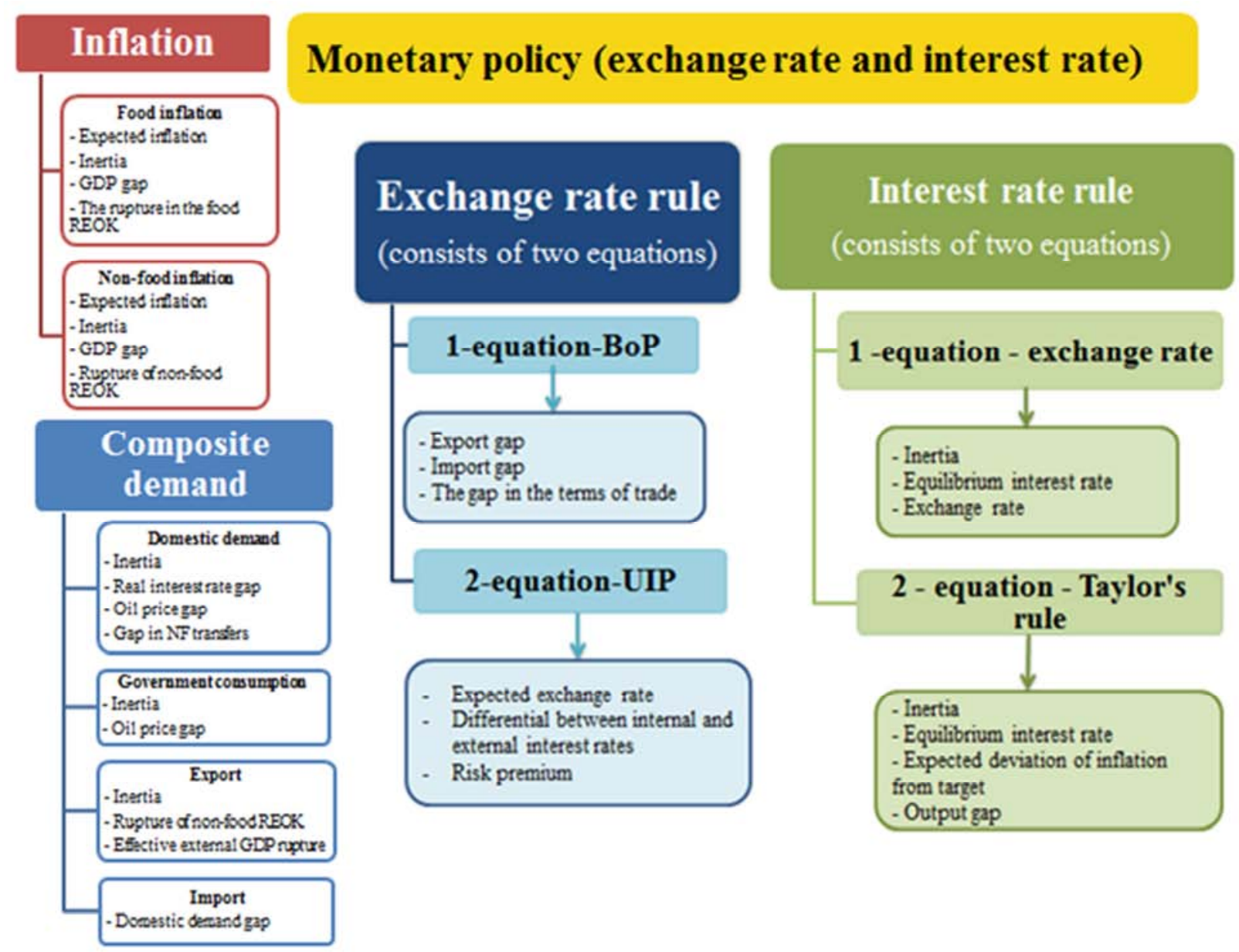

Figure 1. Quarterly predictive model of the NB RK.

As a user association, the Industrial Data Association represents the interests of companies. In particular, the association identifies, analyzes and evaluates the requirements of companies for industrial data and supports the development of a conditional architecture. It is in close and direct contact with representatives of the FMER research project. At the 2nd scientific practical conference of the National Bank of the Republic of Kazakhstan on 
macroeconomic modeling in the analysis and forecasting system, a quarterly forecast model was used. The full versions of the research are posted on the Internet resource of the National Bank of the Republic of Kazakhstan in the Research section. Industrial data forms the foundation for Industry 4.0, providing secure and certified data exchange between companies, while data owners do not lose independence, that is, control over their own data. It thus helps to use and disseminate smart service concepts.

The research project participants are also involved in the platform working groups: business architecture; data and service architecture; software architecture; security architecture.

\section{Methods}

Along all horizontal and vertical cost chains, Industry 4.0 requires a comprehensive digital transformation in equal measure. Digitizing the horizontal cost chain integrates and optimizes the flow of information and goods from customers to suppliers and vice versa through their own company. The process includes the integration and active management of all internal departments of the company (for example, purchasing, manufacturing, logistics and planning). It also includes all external partners in the cost chain that are required to meet customer requirements and provide the required services. The intelligent data management presents in Figure 2 (Smart Data Management) [13].

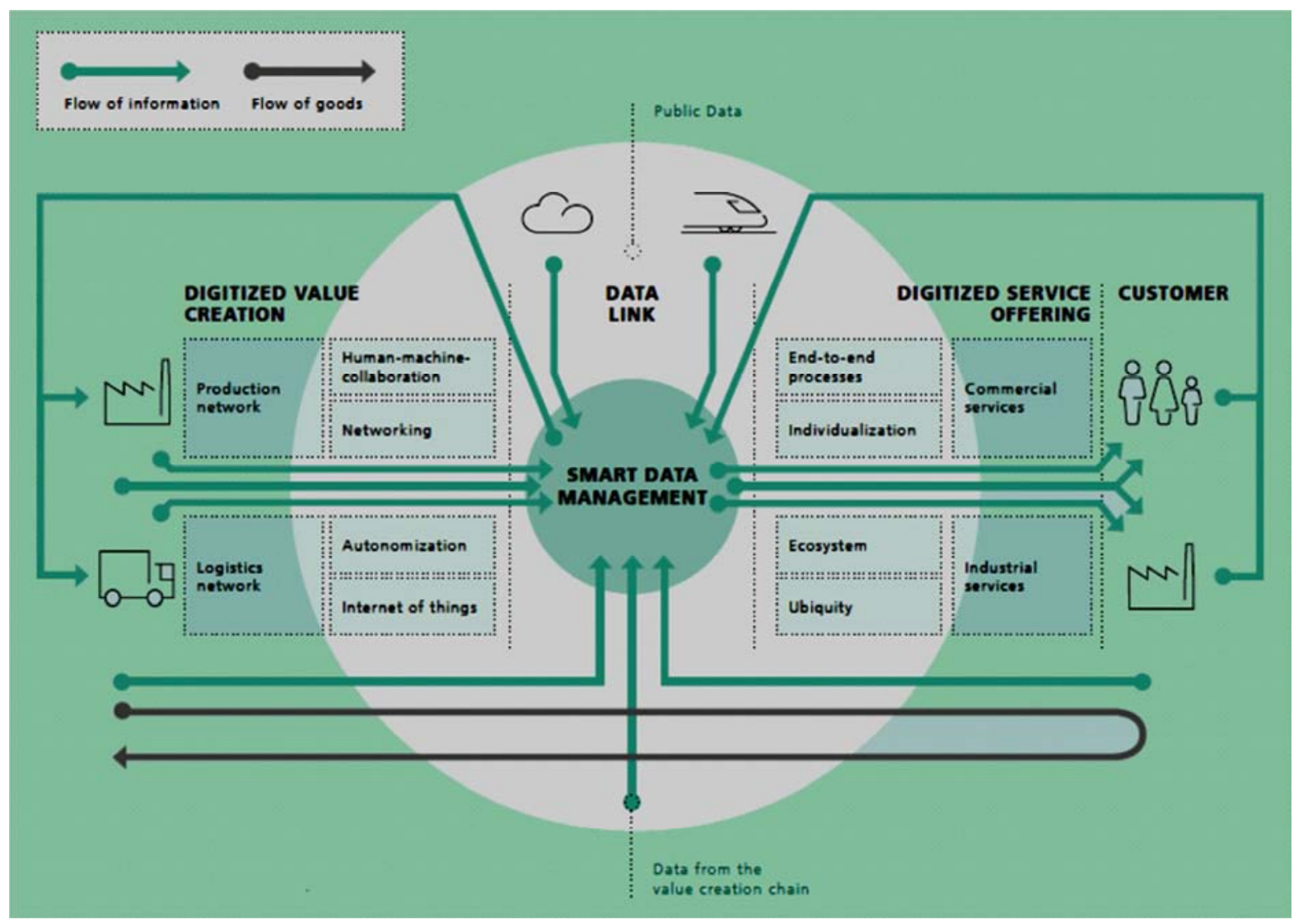

Figure 2. Intelligent cost added data management. Source: FraunhoferGesellschaft (2016).

Digitization is about ensuring a constant flow of information and data from sales through product development and production and logistics. The quality of industrial products with optimal interconnection of production systems is the prevention of system failures and the best analytical skills. Well-integrated engineering along the cost chain is one of the three cornerstones of Industry 4.0. Hence, the data reflects the link between manufacturing and smart services (Figure 2).

The experience of developed countries of the world shows that when solving the problems of transforming the economy into market relations, it is important to distinguish between three stages of analysis. The first stage is the level of goal achievement; the second is the assessment of risks and barriers to the achieved level of the target setting, the third choice of tools for analyzing the innovativeness and effectiveness of the results achieved.

Problem statement is for the digitalization of human capital development. As noted in [4], the definition of approaches to digitalization of human capital development involves the evolutionary development or readaptation of existing analysis tools in three main directions: trade and production relations, socio-economic relations, sociopolitical relations.

The development level of the productive forces of human capital and the degree of its stability are determined by economic laws, which are revealed in the course of the coordination of the economic interests of three social groups 
of individuals employed in the country's economy.

In the process of goods and services reproduction, three types of social relations arise, which arise as a consequence of the development of the productive forces of human capital in three spheres of its expedient activity. These are the directions of development: macroeconomic policy, structural policy, assessment of the regulatory impact on the economy, both from macroeconomic policy and from structural policy.

A. Smith believed that the most effective criterion for measuring the final results of labor is the gross national product (GNP). GNP is obtained after deducting the cost of the current material costs of local resources and attracted from imported goods from the gross output of goods and services, determined in market prices. That is, GNP represents part of the whole. In the conditions of developing countries, such an indicator is now the GDP in market prices or nominal GDP (NGDP), which is also part of the whole, the output of goods and services in market prices. However, Adam Smith did not deny the need to use other sources of measurement of indicators of economic development in the analysis of the economy, including the gross output of goods and services itself. Subsequently, the followers of A. Smith came to the conclusion that in order to measure the index of the physical volume of the product of labor and capital consumed in the country, it is necessary to estimate the price indices or, the same thing, the GDP deflator [10].

In practice, it turns out that nominal GDP in terms of production is determined by the product of the GDP deflator by real GDP, as the basis of a two-structure economy according to the general theory of A. Smith, consisting of economies of the real and financial sectors. To bring this formula in line with the accepted rules of international organizations, the designation $\mu$ was introduced, which expresses the productivity of intermediate consumption (QP). Bearing in mind that nominal GDP (NGDP) is equal to GDP at market prices and its cost is equal to the sum of gross cost added (GVA) and taxes on products and imports minus subsidies on products and imports $(\mathrm{T})$, we can write:

$$
\mu=\mathrm{NGDP} / \mathrm{QP}
$$

The dynamics of the productivity indicator of intermediate consumption actually represents the productivity of current material costs for the production of GDP in market prices or nominal GDP, since by definition

\section{$\mathrm{NX}=\mathrm{NGDP}+\mathrm{QP}$,}

where NX acts as the country's scientific and technological potential in cost terms. The multiplier on the labor theory of cost by Karl Marx follows from the main equation of the system of national accounts, where the output of goods and services at market prices $(\mathrm{NX})$ is equal to the sum of nominal GDP (NGDP) and intermediate consumption (QP):

$$
\mathrm{NX}=\mathrm{NGDP}+\mathrm{QP}
$$

In general, the multiplier has a positive return if the dynamics of the country's scientific and technological potential with $c=\mu /(1+\mu)$ is an increasing function:

$$
\mathrm{c}=\mathrm{NGDP} / \mathrm{NX}=\mu /(1+\mu)
$$

The substantiated classical scientific and technological potential of the country is applicable to the formation of tendencies in determining the production function of cost added from the price of light industry products [5-6].

\section{Result}

The production volume of the light industry of the Republic of Kazakhstan was analyzed in 2015, billion tenge. Source: KS MNE RK, KGD MF RK. In 2015, in the regional context, the main manufacturers of light industry were:

1. Turkistan region is $35 \%$, where the main enterprises of the region can be distinguished: JSC "Melange", JSC "Utex", LLP "AzalaTextile", LLP "Zhanatalap-MT", LLP "Khlopkoprom-Cellulose" LLP "Bal Textile";

2. Almaty city is $14 \%$ with the main enterprises - LLP Kazlegprom-Almaty, LLP Kaz-SPO-N, PKF Kazakhstan Texti-Line Mimioriki;

3. Almaty region is $12 \%$ - Mediateks-N LLP, Glasman LLP, Universal LLP.

In January- June 2016, compared to the same period last year, imports of products decreased 1.6 times and amounted to 441.2 million US dollars, exports amounted to 149.2 million US dollars, which is higher than the same indicator in 2, 2 times in 2015. One reason for the predominance of imports over exports is that exports are predominantly lowcost commodities, while imports are predominantly highcost-added finished goods. Significant volumes of imports of light industry products create competition for domestic goods. However, there are positive developments in the industry [9].

The Union of Light Industry Producers of the Republic of Kazakhstan, created in 2015, in order to increase the share of Kazakhstan content in the production of military uniforms and other work wear, it has united into a consortium of enterprises - raw materials producers and manufacturers of finished products of light industry. A five-year program has also been developed, by the end of which it is planned to reach $100 \%$ of the Kazakh content in raw materials. The consortium undertook to provide uniforms for all military units within five years. Kazakhstan has exemplary examples of doing business, which include the Kazakhstan Text line company with the brand of children's clothing "Mimioriki", "Kaz SPO-N", which dresses foreign athletes, ZIBROO tracksuits are exported to the EAEU countries and the EU, "Semira-Mida" produces outerwear with the brand "SMD", "Glasman" has opened a number of boutiques in the Republic of Kazakhstan and supplies its products to certain countries of the EAEU and the CIS, etc. Kazakhstan designers do not stand aside, developing the domestic light industry. Successful companies are: "AZALA Textile" LLP, which currently produces textile products, "Bal Textile" factory, which produces carpets, has begun cooperation with the world-famous IKEA company [12]. 
It is necessary to overcome the following major problems faced by the light industry of Kazakhstan: lack of qualified personnel that meet modern requirements; tax burden is the need to declare the raw materials imported for production on invoices, paying customs duties, as well as VAT, customs duties; insufficient processing and lack of quality raw materials. Kazakhstan has all the prerequisites for the development of light industry - government support, basic industries, and human resources. To date, the production facilities of the textile industry have been modernized and have the ability to produce high quality textile products. Kazakhstani textile products meet the necessary requirements of generally accepted international standards and regulations, which makes it possible to trade in foreign markets [7].

According to the chief expert of the Center for Sectoral Analysis of Kazakhstan Institute for Industry Development JSC Tolykbekova Aizhan, taking into account the historical and current dynamics of the development of light industry, existing and planned measures of state support for the industry, existing integration (EAEU, WTO), as well as increasing the innovative activity of enterprises, it is possible expect with a high probability an increase in the competitiveness of manufactured products and the development of the industry as a whole.

The study results showed that J. Sachs and F. Laren were really right about the strengths of the model approaches of Keynesianism and monetarists, and the weaknesses can be eliminated by their evolutionary development, by creating a model of a qualitative theory of money. In it, financial capital finds harmony with human capital, and human capital, armed not only with knowledge and technology, but also with physical capital, will become the source of the country's wealth and the welfare of its inhabitants. As a result, the harmonization of the interests of the real and financial sectors of the economy by applying high-quality wages will stimulate the production of maximum surplus profit [11].

\section{Discussion}

The expert's views on innovation systems are usually focused on the national level, and the approach of specialists in the field of global cost chains (GVCs) is inherently global. An innovative approach boils down to finding best practice tools; partners within the innovation system must be equal and states must have a real opportunity to implement the necessary political plans. The GCDS approach focuses on the fact that real economic power belongs and should belong to business in the person of territorial-national complexes [8]. The way out is to pay attention to the concept of national innovation systems. This position is adhered to by innovation experts: IM GCDS are needed to break out of the state that is, to look for the integration possibilities of the two approaches in the synthesis of effective instruments of industrial cooperation.

The formation relevance of digital strategic management is confirmed by the growth of the info communication sector of the economy on a global scale. The study results of the modern digital transformation of companies made it possible to establish that new business models are designed on the basis of digital platforms and are based on the processes of buying and selling not only goods or services, but also information about the users themselves. It has been proven that the digital platform as a technological exchange tool in the modern economy provides mediation processes, actually supporting coordination for the market, creating added cost based on digital cooperation [14]. A methodological approach has been formed to improve the efficiency of digital strategic management problems, taking into account the confirmation of the needs of the cost added chain by creating digital twins of business and technological processes implemented on the basis of block chain technology or on an acyclic graph. The simulation results showed that the coordination effect has a nonlinear dependence on the share of the invested capital of the process organizer, which can be used when searching for optimal design options for interaction platforms and for targeted management of the return on invested capital in the formation of cost chains. The formation relevance of digital strategic management is confirmed by the growth of the info communication sector of the economy on a global scale [15].

\section{Conclusions and Suggestions}

1. Collecting, updating and analyzing data in Kazakhstan's light industry, as well as improving coordination and intensifying information exchange with the private sector, will help to develop capacity in the development and effective implementation of national trade policies. Thanks to its abundant natural resources, Kazakhstan has the opportunity to attract sources of knowledge, skills and modern technologies that the world economy can apply.

2. Over the past decade, the rapid growth of the Kazakh economy has led to a rapid increase in per capita income and a reduction in poverty. Although the global environment is constantly changing, Kazakhstan has all the conditions to use the resource base to expand and deepen development through trade and international integration.

3. Analysis of the trading activities results confirms that in Kazakhstan, the concentration of exports is increasing towards resource conservation and capital intensity of light industry products. At the same time, the concentration of imports in the total volume of production is decreasing.

4. Enhancing the competitiveness of commodity industries by shifting the government's focus from targeted sectoral support to more cross-cutting systemic trade facilitation measures.

5. In Kazakhstan, a large list of domestic services for the light industry is underdeveloped. For job creation and growth prospects, the size and efficiency of the domestic trade services sector, especially basic services by promoting competition, are critical. 
6. Without institutional development, important initiatives can face challenges. Kazakhstan needs to strengthen its institutional capacity in the development and implementation of trade policies of openness to economic development.

\section{References}

[1] Association of light industry enterprises of Kazakhstan. Astana, 2012.

[2] Kazakhstan: the benefits of foreign trade and openness to economic development. Second Integration Report. Astana, 10.07.2012.

[3] Decree of the Government of the Republic of Kazakhstan № 827 dated December 12, 2017. "On approval of the state program" Digital Kazakhstan.

[4] S. Baizakov, B. Khambar, N. Baizakov. Economic and mathematical models of digitalization in Kazakhstan. / Economics and statistics №3, 2018.

[5] Bayzakov S. Architectonics of a meaningful economy: tools for analysis and synthesis of economic indicators: teaching aid / Publishing house of KarSU / Karaganda 2009, p. 121.

[6] Grishchenko A. A. Institutional architectonics and dynamics of economic transformations / Ed. Dan. A. A. Grishchenko / Fort / Kharkiv 2008.

[7] JSC "Institute for economic research". Kazakhstan in the Eurasian Economic Union: the effects of integration. Monograph / Edited by S. N. Alpysbaeva. - Astana, 2017.

[8] Analytical review of the integration processes of Kazakhstan, including the CDS (Digest). Astana, 2015.

[9] A. Aimen, D. Atasheva, D. Khazhgalieva, L. MyrzakhmetSarykulova, A. Dusebaeva. Development problems of light industry in Kazakhstan. Scientific periodical journal
"Izvestiya vuzov. Russia, Technology of the textile industry "№ 2, 2020, p. 42-47.

[10] D. M. Khazgaleeva, Z. H. Kuatbekov, Sarsenova A. E., A. T. Aimen, S. B. Kadyrbay Problems of formation and development of cluster economy using the example of light industry of the Republic of Kazakhstan. Scientific periodical journal "Izvestiya vuzov. Russia, Technology of the textile industry "№ 2, 2020, p. 53-56.

[11] A. Aimen, I. Suleimenova. Assessment of the competitive positions of the Zhambyl region of the Republic of Kazakhstan in the context of the globalization of the world economy. Quarterly scientific and information journal "Economics and Statistics", № 1, 2021, p. 182-191.

[12] ZH. U. Myrhalykov, A. M. Yessirkepova, G. K., Issayeva, B. S. Kulbai. To the problem of the evaluation methods of synergetic effect in the secondary re-sources management on the textile industry "Izvestiya vuzov. Russia, Technology of the textile industry "№ 2, 2015, №1, p. 5-10.

[13] A. M. Yessirkepova, G. K. Issayeva., A. N. Aitymbetova., Zhadigerova G. A., A. A. Abdikadirova. Financial aspects of dual education as modernization bases for personnel training for textile industry Scientific periodical journal. "Izvestiya vuzov. Russia, technology of the textile industry "№ 6, 2017, p. 78-84.

[14] Report of the Association of Light Industry of Kazakhstan within the framework of the grant program of the SShA International Development Agency (USAID) project on international development to improve the business environment " Research of problems of small and mediumsized businesses in the light industry sector of the Republic of Kazakhstan-. - 2016, June. p. 7.

[15] M. K. Seidakhmetov, A. M. Yessirkepova, A. S. Tulemetova, Z. A. Bigeldiyeva, B. S. Mukhan. Improving the model for managing the competitiveness of textile enterprises products of the Republic of Kazakhstan. Scientific Periodical Journal. "Izvestiya Vuzov. Russia, Technology Of The Textile Industry "№ 2, 2020, P. 5-12. 